\title{
ANALISIS KELAYAKAN EKONOMI PROYEK PEMBANGUNAN GEDUNG OLAHRAGA (GOR) KABUPATEN BANGKA
}

\author{
Junita Eka Susanti \\ Email : junita.susanti@si.itera.ac.id \\ Miskar Maini \\ Email : miskar.maini@si.itera.ac.id
}

Program Studi Teknik Sipil Jurusan Teknologi Infrastruktur dan Kewilayahan Institut Teknologi Sumatera (ITERA) Kampus Terpadu ITERA, Jati Agung, Kabupaten Lampung

Selatan

\begin{abstract}
ABSTRAK
Dalam kegiatan pekerjaan konstruksi, analisa kelayakan pembangunan dipergunakan sebagai bahan acuan bagi pelaksana pembangunan dan menjadi standar layak atau tidaknya pembangunan suatu infrastruktur di suatu wilayah, terutama pembangunan fasilitas umum seperti pembangunan Gedung Olahraga (GOR) untuk kepentingan olahraga di suatu wilayah ataupun negara. Kemajuan prestasi olahraga suatu bangsa juga dapat mengangkat kehomatan dan nama bangsa itu sendiri. Penambahan fasilitas olahraga pada daerah atau wilayah tertentu yang kurang atau belum tersedia fasilitas olahraga merupakan tanggung jawab bersama baik pemerintah maupun swasta. Hal ini dikarenakan, GOR merupakan salah satu fasilitas publik yang perlu disediakan pemerintah dalam rangka untuk menunjang kegiatan olahraga.

Penelitian ini bertujuan untuk menganalisis investasi proyek pembangunan gedung olah raga (GOR). Adapun alat analisis yang digunakan dalam penelitian ini adalah dengan menggunakan Studi Kelayakan Aspek Keuangan yaitu dengan metode Net Present Value (NPV) Internal Rate of Return (IRR), Payback Period (PP).

Berdasarkan hasil analisis menunjukan nilai Payback Periode (PP) sebesar 12 tahun 3 bulan lebih kecil dari nilai ekonomis (20) tahun kemudian Nilai Net Present Value (NPV) pada Discount Factor 7\% sebesar Rp. 30.433.056. Baik secara PP maupun NPV dan IRR Pembangunan Gedung Olahraga Tipe B Kabupaten Bangka dikatakan layak apabila nilai NPV positif, pada Discount Factor $7 \%$ positif yang pembangunan GOR layak dijalankan.
\end{abstract}

Kata Kunci : GOR, $N P V$, IRR

\section{PENDAHULUAN}

$\begin{array}{ccc}\text { Dalam } & \text { kegiatan } & \text { pekerjaan } \\ \text { konstruksi, } & \text { analisa } & \text { kelayakan }\end{array}$ pembangunan dipergunakan sebagai bahan acuan bagi pelaksana pembangunan dan menjadi standar layak atau tidaknya pembangunan suatu infrastruktur di suatu wilayah, terutama pembangunan fasilitas umum seperti pembangunan Gedung Olahraga (GOR) untuk kepentingan olahraga di suatu wilayah ataupun negara. Kemajuan prestasi olahraga suatu bangsa juga dapat mengangkat kehomatan dan nama bangsa itu sendiri. Penambahan fasilitas olahraga pada daerah atau wilayah tertentu yang kurang atau belum tersedia fasilitas olahraga merupakan tanggung jawab bersama baik pemerintah maupun swasta.

Perencanaan GOR pada dasarnya adalah suatu upaya dalam menetapkan fasilitas fisik, peralatan, tenaga dan sumber dana yang diperlukan untuk memberikan 
pelayanan olahraga bagi masyarakat sesuai dengan kebutuhan.

Adapun tujuan dari penelitian ini adalah untuk menganalisis investasi proyek pembangunan gedung olah raga (GOR). Adapun alat analisis yang digunakan dalam penelitian ini adalah dengan menggunakan Studi Kelayakan Aspek Keuangan yaitu dengan metode Net Present Value (NPV) Internal Rate of Return (IRR), Net Benefit Cost Ratio (Net BCR), Gross Benefit Cost Ratio (Gross BCR), Profitability Ratio (PR), Payback Period (PP), Break Even Point (BEP).

\section{TINJAUAN PUSTAKA}

Rahmalia, dkk (2016) meneliti analisa kelayakan pembangunan jalan tol Pemalang Batang metodologi yang digunakan meliputi: evaluasi kinerja jalan Pantura menggunakan MKJI 1997; analisa lalu lintas yang teralihkan ke jalan tol menggunakan kurva diversi; analisa kelayakan ekonomi terhadap penghematan BOK, penghematan waktu dan penghematan biaya kecelakaan; analisa kelayakan finansial terhadap $N P V, B C R$, $I R R$, payback period dan $N P V=0$; dan analisa sensitivitas terhadap penurunan pendapatan, batas tahun awal pemasukan pendapatan, perubahan suku bunga tarif TOL, tahun awal pemasukan pendapatan dan batas kenaikan biaya investasi. Jalan tol Pemalang - Batang layak secara ekonomi. Penghematan BOK untuk Gol I sebesar Rp 23,49; Gol IIA sebesar Rp 39.237,66 dan Gol IIB sebesar Rp kelayakan bisnis ini menunjukkan pembangunan Pusat Perbelanjaan layak untuk dilaksanakan, baik dari aspek
52.518,90. Penghematan waktu untuk Gol I sebesar 27.98 menit, Gol IIA sebesar 45.745 menit dan Gol IIB sebesar 63.02 menit. Biaya kecelakaan dapat dihemat sebesar Rp 43.363.019,00/tahun/km. Jalan tol Pemalang - Batang juga layak secara finansial dengan nilai $N P V=\mathrm{Rp}$ 4.301.297.387.339,00; nilai $B C R=1.787$; nilai $I R R=23.226 \%$; payback period terjadi pada 8 tahun 7 bulan 16 hari; dan $N P V=0$ terjadi pada 13 tahun 7 bulan 23 hari. Hasil analisa sensitivitas adalah batas penurunan persentase pendapatan sebesar $44.032 \%$, batas awal pemasukan pendapatan pada tahun ke -21 , dan batas kenaikan biaya investasi sebesar $78.673 \%$. Sedangkan perubahan suku bunga tarif tol tidak berpengaruh terhadap kelayakan finansial.

Sutika, dkk (2017) meneliti studi kelayakan pembangunan Pusat Perbelanjaan Cokrominoto, penelitian ini tentang evaluasi rencana investasi pada Pusat Perbelanjaan Cokroaminoto yang direncanakan oleh Pemerintah Kota Denpasar. Penyediaan fasilitas berupa pembangunan Pusat Perbelanjaan yang berlokasi di Jalan Cokroaminoto, Desa Pemecutan Kaja, Denpasar. Penelitian ini dilakukan dengan tujuan untuk mengetahui kelayakan pada rencana pengembangan aset pemerintah yang akan direvitalisasi menjadi Pusat Perbelanjaan dari aspek hukum, teknis dan manajemen, pasar dan pemasaran, sosial, dan aspek keuangan. Data dikumpulkan dengan metode observasi dan wawancara. Hasil kajian hukum, teknis dan manajemen, pasar dan pemasaran, sosial, dan aspek keuangan. Kajian dari aspek keuangan ditunjukkan 
oleh $A R R$ sebesar 50,32\%; PP 4,6 tahun; $N P V$ positif sebesar Rp 95.747.663.065; dan PI 1,83 kali.

\section{LANDASAN TEORI}

Analisis ekonomi

suatu pembangunan proyek memberikan gambaran tentang rencana penggunaan sumber anggaran yang dimiliki, sehingga dapat diketahui tingkat pengembalian biaya yang akan diinvestasikan. Dengan demikian maka pihak pemilik/ investor dapat melihat tingkat keuntungan yang mungkin akan diperoleh.

Adapun aspek keuangan yang akan dianalisis terdiri dari:

1. Rencana Investasi dan Sumber Dana

2. Proyeksi Pendapatan dan Biaya

3. Proyeksi Cash Flow

4. Analisis Keuangan : Break Event Point (BEP), Internal Rate of Return (IRR), dan Net Present Value (NPV)

\section{Pay Back Periode}

Alat analisis ini digunakan untuk menentukan layak tidaknya usulan pembangunan Gedung Olahraga tipe $\mathrm{C}$ Kab Bangka dengan membandingkan antara waktu pengembalian jumlah dana untuk investasi dengan umur ekonomi proyek. Metode pemulihan investasi ini untuk menilai jangka waktu pemulihan seluruh modal yang diinvestasikan dalam proyek.

$$
P P=\frac{\text { Nilai Investasi }}{\text { Pendapatan }} x 1 \text { tahun }
$$

Jika nilai payback periode (PP) lebih kecil dari 20 tahun, maka pembangunan Gedung Olahraga tipe C Kab Bangka layak didirikan atau proyek layak apabila masa pemulihan modal investasi lebih pendek dari usia ekonomisnya. Perhitungannya adalah tahun dimana nilai akumulasi penerimaan bersih $\geq 0$.

\section{Net Present Value (NVP)}

$N P V$ adalah salah satu kreteria yang dipakai untuk menolak atau menerima suatu investasi dengan dasar mencari nilai bersih sekarang pada discount rate tertentu. Ternik analisis ini digunakan untuk mengetahui apakah suatu usulan proyek investasi dilaksanakan atau tidak dengan cara mengurangkan antara present value dan aliran kas bersih operasional atas proyek investasi selama umur ekonomis, termasuk terminal cash flow dan initial cash flow.

$$
N P V=-A o+\sum_{t=1}^{n} \frac{A_{t}}{(1+r)^{t}}
$$

Dimana:

$-A o=$ pengeluaran investasi pada tahun ke 0

$A t=$ aliran kas masuk bersih pada tahun ke $\mathrm{t}$

$r=$ tingkat keuntungan yang disyaratkan oleh para pemilik modal sendiri dengan hanya memperhatikan resiko usaha

$n=$ jumlah tahun (usia ekonomis) proyek.

Jika NPV positif, proyek dilaksanakan dan sebaliknya jika $N P V$ negatif, pembangunan Gedung Olahraga Kab Bangka tidak layak. Dan jika nilai $N P V=0$, berarti tingkat bunga proyek sama dengan tingkat bunga berlaku.

\section{Financial Internal Rate of Return (FIRR)}

Internal rate of return atau tingkat pengembalian internal adalah tingkat suku bunga dari suatu proyek dalam jangka waktu tertentu. Konsep dalam analisis ini untuk menentukan apakah suatu usulan 
proyek investasi dianggap layak atau tidak, dengan cara membandingkan antara FIRR dengan tingkat keuntungan yang diharapkan. Perhitungan FIRR dengan cara mencari discount rate yang dapat menyamakan antara present value dari aliran kas dengan present value dari investasi.

$$
F I R R=i_{t}+\frac{N P V_{1}}{N P V_{1}+N P V_{2}} x\left(i_{2}-i_{1}\right)
$$

Dimana:

\section{FIRR = Financial Internal Rate of Return}

$i_{1}=$ tingkat discount rate yang menghasilkan $N P V_{1}$

$i_{2}=$ tingkat discount rate yang menghasilkan $N P V_{2}$

$N P V_{1}=N P V$ pada tingkat bunga $i_{1}$ $N P V_{2}=N P V$ pada tingkat bunga $i_{2}$

Informasi ini sangat penting bagi investor karena hasil perhitungan FIRR yang menunjukkan angka lebih kecil dari tingkat bunga acuan (12\%) yang berlaku akan membatalkan suatu rencana investasi walaupun semua aspek dinilai layak.

\section{METODE PENELITIAN}

Persiapan pada penelitian analisa kelayakan adalah tahapan melakukan kompilasi data dari seluruh data yang didapat dari hasil pengumpulan data yang terdiri dari data primer dan data sekunder. Pengumpulan data primer, dapat dilakukan dengan melalui proses pengamatan atau observasi langsung / pengamatan atau observasi lapangan sehingga akan didapat seluruh informasi atau data secara visual pada wilayah perencanaan. pengumpulan data primer dapat pula dilakukan dengan cara wawancara atau tanya jawab kepada instansi-instansi dan pihak-pihak lain yang berkaitan dengan pekerjaan penyusunan ini dan atau dengan langsung kepada masyarakat umum selaku salah satu pelanggan dari gedung olahraga. sifat wawancara bersifat terbuka artinya pengambilan data tidak terpatok pada kuesioner namun dapat dikembangkan secara lisan dengan responden. secara garis besar data yang didapat dari pengumpulan data primer adalah :

1. Kondisi Potensi Lahan/ Lokasi

2. Informasi langsung lainnya yang terkait dengan Kondisi dan Potensi yang ada terkait dengan Standar/ Pedoman dan Ketentuan yang berlaku serta Sasaran dari Rencana Pembangunan/ Pengembangan Gedung Olahraga serta informasi keinginan yang ada.

Pengambilan Data Sekunder, dapat dilakukan dengan mendatangi pula masing-masing Instansi lainnya yang berkaitan sesuai dengan data yang dibutuhkan dalam pekerjaan penyusunan ini. Jika pada salah satu Instansi ternyata Data tidak dipunyai, atau sedang dalam proses pembuatan, atau sedang digunakan untuk keperluan lain maka konsultan dapat mencari pada Instansi lain yang terkait sesuai dengan kebutuhan data. Untuk melaksanakan pekerjaan ini diperlukan Data Internal/Data Dalam dari fasilitas Olahraga yang ada dan atau fasilitas olahraga di wilayah sekitarnya,

Selanjutnya melaksanakan Analisis Keuangan memberikan gambaran tentang rencana penggunaan sumber anggaran yang dimiliki, sehingga dapat diketahui tingkat pengembalian biaya yang akan 
diinvestasikan. Dengan demikian maka pihak pemilik/ investor dapat melihat tingkat keuntungan yang mungkin akan diperoleh.

Adapun aspek keuangan yang akan dianalisis terdiri dari:

1. Rencana Investasi dan Sumber Dana

2. Proyeksi Pendapatan dan Biaya

3. Proyeksi Cash Flow

4. Analisis Keuangan : Internal Rate of Return (IRR), dan Net Present Value (NPV)

\section{HASIL DAN PEMBAHASAN}

\section{Analisis Keuangan, Rencana Investasi} dan Sumber Dana

Proyek Pembangunan Gedung Olahraga (GOR) secara umum diharapkan mampu meningkatkan pelayanan terhadap masyarakat baik segi keamanan maupun dalam segi kenyamanan untuk menunjang kegiatan olahraga di Kabupaten Bangka. Secara Ekonomi diharapkan dapat meningkatkan pendapatan, sehingga dapat memenuhi target yang telah ditetapkan Pemerintah Daerah Kabupaten Bangka. Selain itu, pendapatan dari sektor retribusi dan sewa diharapkan mampu memberikan kontribusi yang cukup besar pada pendapatan GOR sebagai nilai investasi daerah.

Analisis Keuangan memberikan gambaran tentang rencana penggunaan sumber anggaran yang dimiliki, sehingga dapat diketahui tingkat pengembalian biaya yang akan diinvestasikan. Dengan demikian maka pihak pemilik/ investor dapat melihat tingkat keuntungan yang mungkin akan diperoleh. Adapun aspek keuangan yang akan dianalisis terdiri dari rencana investasi dan dasar perhitungan sumber dana

Pembahasan mengenai rencana investasi, menyangkut keseluruhan biaya yang dibutuhkan untuk pembangunan Gedung olahraga Tipe B Kabupaten Bangka sampai siap operasi, tetapi tidak termasuk biaya pembelian lahan (karena lahan yang dipakai milik pemerintah daerah Kabupaten Bangka).

Besarnya biaya tiap $\mathrm{M}^{2}$ luas lantai bangunan akan diambil dari biaya standar bangunan gedung negara, sesuai dengan Peraturan Bupati Kabupaten Bangka (Harga gedung bertingkat sederhana Rp $5.550 .000 / \mathrm{m}^{2}$ dan Tidak Sederhana $\mathrm{Rp}$ $6.340 .000 \mathrm{~m}^{2}$.

Tabel 1 Koefesien Perhitungan Biaya

Lantai

\begin{tabular}{|c|c|c|}
\hline No & $\begin{array}{c}\text { Jumlah Lantai } \\
\text { Bangunan }\end{array}$ & $\begin{array}{c}\text { Koefisien untuk } \\
\text { Perhitungan } \\
\text { Harga Per } \mathbf{~ m}^{2}\end{array}$ \\
\hline 1 & Bangunan 1 lantai & 1,000 \\
\hline 2 & Bangunan 2 lantai & 1,090 \\
\hline
\end{tabular}

\section{Analisis Biaya Pelaksanaan Konstruksi}

Sesuai dengan kebutuhan ruang dalam pembangunan Gedung olahraga Tipe B Kabupaten Bangka. Berikut ini merupakan akumulasi jumlah luasan dan nilai investasi yang digunanakan dalam pembangunan. Dari analisis kebutuhan ruang, bahwa pembangunan Gedung olahraga akan dilaksanakan dalam 2 lantai. Dengan kebutuhan pada lantai 1 arena olahraga dan lantai 2 tribun penonton. Berikut ini tabel dari akumulasi jumlah kebutuhan ruang. 
Tabel 2 Perhitungan Biaya Struktur dan Arsitektur

\begin{tabular}{|c|c|c|c|c|}
\hline $\begin{array}{l}\text { Keterangan } \\
\text { Bangunan }\end{array}$ & Luas $m 2$ & $\begin{array}{l}\text { Koefiefien Perhitungan } \\
\text { Lantai }\end{array}$ & Asumsi Biaya & Total Biaya \\
\hline Parkir & 1200 & 1,000 & 3.000 .000 & 3.000 .000 .000 \\
\hline Zona Bebas & 630 & 1,000 & 1.000 .000 & 630.000 .000 \\
\hline Total Lantai 1 & 2092 & 1,000 & 6.340 .000 & 13.263 .280 .000 \\
\hline Total Lantai 2 & 1.076 & $(0.5) * 1,090$ & 6.340 .000 & 3.983 .280 .618 \\
\hline \multicolumn{4}{|c|}{ Total Biaya Investasi } & 20.611 .390 .118 \\
\hline $\begin{array}{l}\text { Luas Site ruangan } \\
\text { dibutuhkan }\end{array}$ & 3.168 & & \multirow[t]{2}{*}{ Investasi / $\mathrm{m}^{2}$} & 6.505.997 \\
\hline Luas Site Total & 4.998 & & & 4.123 .878 \\
\hline
\end{tabular}

Dari hasil akumulasi jumlah kebutuhan lantai yang digunakan dengan total ruang dalam seluas $3.048 \mathrm{~m}^{2}$. Biaya pekerjaan sipil, struktur dan arsitektur sebesar Rp. 20.196.754.118,- maka diperoleh biaya rata-rata tiap $1 \mathrm{~m}^{2}$ luas bangunan adalah sebesar Rp. 6.626.101.-

Perkiraan Modal Kerja dan Proyeksi Rencana Proyek

Lokasi rencana pembangunan GOR Kab. Bangka terletak di Jalan Lingkar Timur Kec. Merawang Kab. Bangka dengan luas lahan $20.065 \mathrm{~m} 2$ dan luas bangunan 3.048 $\mathrm{m} 2$. Jadwal rencana proyek awal tahap perencanaan proyek dilaksanakan tahun
2020 dengan masa pelaksanaan pembangunan 1 tahun, maka awal tahap operasional Gor akan terjadi pada tahun 2021 dengan umur rencana proyek 20 tahun.

Sumber dana untuk pembangunan Gedung olahraga Tipe B Kabupaten Bangka berasal dari modal Pemerintah Daerah Kabupaten Bangka, pinjaman bank dan hibah dari pemerintah pusat dengan rincian modal sendiri sebesar Rp. 1.000.000.000, Pinjaman Bank Rp. 6.661.390.118 dan hibah pemerintah pusat yaitu sebesar Rp. 14.000.000.000 sehingga total sumber dana sebesar Rp. $\quad 15.000 .000 .0000$

Tabel 3 Proyeksi Sumber Dana

\begin{tabular}{|l|l|l|l|l|}
\hline No & Uraian & Persentase & Jumlah & Tahap \\
\hline 1 & Modal Sendiri & $4.63 \%$ & 1.000 .000 .000 & Persiapan \\
\hline 2 & Pinjaman Bank & $30.59 \%$ & 6.661 .390 .118 & \multirow{2}{*}{ Konstruksi } \\
\hline 3 & Hibah & $64.78 \%$ & 14.000 .000 .000 & \\
\cline { 1 - 3 } Total & & $\mathbf{2 0 . 6 1 1 . 3 9 0 . 1 1 8}$ & \\
\hline
\end{tabular}

Sumber : Dinas Pariwisata, Kepemudaan dan Olahraga Kabupaten Bangka, 2019

\section{Proyeksi Pendapatan dan Biaya}

Perhitungan proyeksi pendapatan yang diharapkan berbasis pada beberapa hal penting yaitu :
1) Luas efektif properti, yaitu luas ruang yang bisa memperoleh pendapatan, misalnya ruang rawat inap, poliklinik dan ruang lainnya serta 
perbandingannya dengan luas keseluruhan bangunan (proyek) beserta semua equipment dan requirment sehingga proyek dapat beroperasi secara sempurna sesuai dengan yang diharapkan

2) Komposisi modal antara modal sendiri (equity) dan modal dari pinjaman (loan) berikut DRE (Discout Rate of Equity) dan suku bunga pinjaman (interest rate).

3) Lama waktu dikonstruksi (pelaksanaan pembangunannya), berkaitan dengan waktu mulai proyek beroperasi, semakin cepat semakin baik karena investasi yang ditanam tidak membengkak sesuai dengan DRC (Dicount Rate of Capital).

4) Umur efektif properti (proyek) yang diperhitungkan.

5) Periode pencairan investasi, yang juga berpengaruh besar terhadap perhitungan pendapatan yang diharapkan.

Dengan memperhatikan hal-hal di atas, akan diperoleh hasil perhitungan dengan matrik seperti terlihat pada tabel berikut ini:

Tabel 4 Asumsi Nilai Investasi Gedung olahraga Tipe B Kabupaten Bangka

\begin{tabular}{|l|l|l|l|l|l|}
\hline No & Ruang & Luas/m & Investasi/m & Jumlah Ruang & Total Investasi \\
\hline 1 & Arena Lapangan & 1134 & 6.340 .000 & 1 & 7.189 .560 .000 \\
\hline 2 & Tribun Penonton & 1076 & 6.340 .000 & 2000 & 3.983 .280 .618 \\
\hline \multicolumn{2}{|l|}{ Total } & $\mathbf{2 2 1 0}$ & & & $\mathbf{1 1 . 1 7 2 . 8 4 0 . 6 1 8}$ \\
\hline
\end{tabular}

Dari rincian hasil asumsi investasi gedung olahraga tipe B Kabupaten Bangka yang dihasilkan dari total luasan ruang yang memiliki investasi sebesar $2210 \mathrm{~m}^{2}$ yang terdiri dari arena lapangan dan tribun penonton menghasilkan nilai invetasi sebesar Rp. 11.172.840.618,00.

\section{Biaya Operasional Gedung Olahraga}

Perhitungan biaya operasional yang diharapkan berbasis pada beberapa hal penting yaitu: asumsi biaya tenaga langsung dan asumsi biaya penunjang seperti pembelian bahan, pemeliharaan gedung, pelatihan karyawan dan menejemen pengelolaan. Dari rincian hasil asumsi biaya operasional gedung olahraga tipe B Kabupaten Bangka yang terdiri dari pembayaran biaya beban dan biaya penunjang lainnya menghasilkan total biaya operasional sebesar Tahun pertama sebesar Rp. 289.727.802.00

\section{Net Present Value (NPV)}

Jika NPV positif, pembangunan gedung olahraga tipe B Kabupaten Bangka layak dan sebaliknya jika $P V$ negatif pembangunan gedung olahraga Tipe B Kabupaten Bangka tidak layak dibangun. Dan jika nilai $N P V=0$, berarti tingkat bunga proyek sama dengan tingkat bunga berlaku. Sedangkan IRR merupakan informasi sangat penting bagi gedung olahraga Tipe B Kabupaten Bangka karena hasil perhitungan IRR yang menunjukkan angka lebih kecil dari tingkat bunga acuan (4\%-6\%) yang berlaku akan membatalkan suatu rencana investasi bagi Gedung olahraga Tipe B Kabupaten Bangka. 
Tabel 5 Proyeksi Net Present Value (NPV) Dengan Discount Factor (DF=10\%)

\begin{tabular}{|c|c|c|c|c|c|c|c|c|}
\hline No & Tahun & E.A.T (Rp.) & $\begin{array}{l}\text { Penyusutan } \\
\text { (Rp) }\end{array}$ & $\begin{array}{l}\text { Kas Bersih } \\
\text { (Process) } \\
\text { (Rp) }\end{array}$ & $\begin{array}{l}\text { Discount } \\
\text { Factor } \\
\text { (DF) }\end{array}$ & $\begin{array}{l}\text { PV Kas Bersih } \\
\text { (Rp) }\end{array}$ & $\begin{array}{l}\text { Discount } \\
\text { Factor } \\
\text { (DF) }\end{array}$ & $\begin{array}{l}\text { PV Kas } \\
\text { Bersih (Rp) }\end{array}$ \\
\hline & & & & & $8 \%$ & & $10 \%$ & \\
\hline 1 & Tahun ke-1 & $-30,143,802$ & $264,455,605$ & $234,311,802$ & 0,649 & $218,982,993$ & 0,643 & $216,955,373$ \\
\hline 2 & Tahun ke-2 & $5,842,198$ & $132,227,802$ & $138,070,000$ & 0,606 & $120,595,685$ & 0,595 & $118,372,771$ \\
\hline 3 & Tahun ke-3 & $80,615,698$ & $132,227,802$ & $212,843,500$ & 0,567 & $173,743,697$ & 0,551 & $168,962,033$ \\
\hline 4 & Tahun ke-4 & $195,782,873$ & $132,227,802$ & $328,010,675$ & 0,530 & $250,237,773$ & 0,510 & $241,097,638$ \\
\hline 5 & Tahun ke-5 & $443,820,970$ & $132,227,802$ & $576,048,773$ & 0,495 & $410,714,814$ & 0,473 & $392,049,115$ \\
\hline 6 & Tahun ke-6 & $523,788,140$ & $132,227,802$ & $656,015,942$ & 0,463 & $437,131,122$ & 0,438 & $413,401,321$ \\
\hline 7 & Tahun ke-7 & $501,286,862$ & $132,227,802$ & $633,514,664$ & 0,433 & $394,521,094$ & 0,405 & $369,649,722$ \\
\hline 8 & Tahun ke-8 & $494,393,168$ & $132,227,802$ & $626,620,971$ & 0,404 & $364,699,110$ & 0,375 & $338,543,813$ \\
\hline 9 & Tahun ke-9 & $513,094,911$ & $132,227,802$ & $645,322,713$ & 0,378 & $351,012,798$ & 0,347 & $322,822,021$ \\
\hline 10 & Tahun ke-10 & $510,307,969$ & $132,227,802$ & $642,535,771$ & 0,353 & $326,632,605$ & 0,322 & $297,618,385$ \\
\hline 11 & Tahun ke-11 & $708,756,030$ & $132,227,802$ & $840,983,832$ & 0,330 & $399,545,361$ & 0,298 & $360,683,551$ \\
\hline 12 & Tahun ke-12 & $700,863,045$ & $132,227,802$ & $833,090,847$ & 0,308 & $369,902,299$ & 0,276 & $330,831,838$ \\
\hline 13 & Tahun ke-13 & $785,820,889$ & $132,227,802$ & $918,048,691$ & 0,288 & $380,957,568$ & 0,256 & $337,564,598$ \\
\hline 14 & Tahun ke-14 & $777,364,536$ & $132,227,802$ & $909,592,339$ & 0,269 & $352,755,591$ & 0,236 & $309,680,755$ \\
\hline 15 & Tahun ke-15 & $768,608,839$ & $132,227,802$ & $900,836,641$ & 0,251 & $326,504,655$ & 0,219 & $283,981,279$ \\
\hline 16 & Tahun ke-16 & $987,251,899$ & $132,227,802$ & $1,119,479,701$ & 0,235 & $379,206,506$ & 0,203 & $326,765,453$ \\
\hline 17 & Tahun ke-17 & $1,088,502,443$ & $132,227,802$ & $1,220,730,245$ & 0,220 & $386,451,933$ & 0,188 & $329,925,483$ \\
\hline 18 & Tahun ke-18 & $\begin{array}{l}1,078,771,394 \\
\end{array}$ & $132,227,802$ & $1,210,999,197$ & 0,206 & $358,290,965$ & 0,174 & $303,051,373$ \\
\hline 19 & Tahun ke-19 & $1,068,687,444$ & $132,227,802$ & $1,200,915,246$ & 0,192 & $332,063,073$ & 0,161 & $278,266,550$ \\
\hline \multirow[t]{2}{*}{20} & Tahun ke-20 & $1,059,145,620$ & $132,227,802$ & $1,191,373,422$ & 0,179 & $307,873,532$ & 0,149 & $255,607,032$ \\
\hline & & $613,128,056$ & & & & $6,641,823,174$ & & $5,995,830,104$ \\
\hline
\end{tabular}

Internal Rate of Return (IRR)

Pada tabel NPV menunjukan bahwa nilai $N P V$ pada tahun ke-20 sebesar
Rp.6.641.823.174,- lebih besar dari Total $P V$ investasi Rp. 5.995.830.104,-

Tabel 6 Proyeksi Internal Rate of Return (IRR)

\begin{tabular}{|l|l|}
\hline Total PV investasi & 6.641 .823 .174 \\
\hline NPV (DF: 7\%) & 30.433 .056 \\
\hline NPV (DF: 8\%) & -615.560 .014 \\
\hline IRR & $7.05 \%$ \\
\hline
\end{tabular}

Pada tabel diatas nilai $N P V$ pada Discount Factor 7\% sebesar Rp 30.433.056 dan pada Discount Factor 8\% sebesar 615.560.014. Pembangunan Gedung olahraga Tipe B Kabupaten Bangka dikatakan layak apabila nilai $N P V$ positif, pada tabel diatas nilai $N P V$ pada Discount Factor $7 \%$ positif yang berarti bahwa pada Discount Factor 7\% pembangunan gedung layak dijalankan.

\section{Pay Back Periode (PP)}

Nilai Payback Periode (PP) dalam penelitian ini adalah suatu periode yang menunjukan berapa lama modal yang ditanamkan dalam proyek dapat kembali/pengembalian biaya investasi. Estimasi nilai kas bersih setiap tahun berubah, maka metode perhitungan yang digunakan dalam penelitian ini adalah menggunakan metode di mana kas bersih setiap tahun tidak sama/berbeda maka $P P$ 
dapat dicari dengan mengurangi investasi awal dengan aliran kas bersih pertama sampai aliran kas bersih tidak dapat dikurangi denan aliran kas bersih tahun berikutnya, kemudian sisa kas bersih tahun tersebut dibagi dengan kas bersih tahun berikutnya dan dikalikan 1 tahun (12 bulan), perhitungan $P P$ seperti tabel dibawah ini:

Tabel 7 Proyeksi Payback Periode (PP)

\begin{tabular}{|l|l|l|l|}
\hline Tahun ke- & EAT $(\mathbf{R p})$ & Aliran Kas Bersih $(\mathbf{R p )}$ & Kumulatif Aliran Kas (Rp) \\
\hline Nilai Investasi & & & $6,611,390,118$ \\
\hline 1 & $-30,143,802$ & $234,311,802$ & $6,377,078,316$ \\
\hline 2 & $5,842,198$ & $138,070,000$ & $6,239,008,316$ \\
\hline 3 & $80,615,698$ & $212,843,500$ & $6,026,164,816$ \\
\hline 4 & $195,782,873$ & $328,010,675$ & $5,698,154,141$ \\
\hline 5 & $443,820,970$ & $576,048,773$ & $5,122,105,368$ \\
\hline 6 & $523,788,140$ & $656,015,942$ & $4,466,089,426$ \\
\hline 7 & $501,286,862$ & $633,514,664$ & $3,832,574,762$ \\
\hline 8 & $494,393,168$ & $626,620,971$ & $3,205,953,791$ \\
\hline 9 & $513,094,911$ & $645,322,713$ & $2,560,631,078$ \\
\hline 10 & $510,307,969$ & $642,535,771$ & $1,918,095,307$ \\
\hline 11 & $708,756,030$ & $840,983,832$ & $1,077,111,475$ \\
\hline 12 & $700,863,045$ & $833,090,847$ & $244,020,627$ \\
\hline 13 & $785,820,889$ & $918,048,691$ & $(674,028,064)$ \\
\hline 14 & $777,364,536$ & $909,592,339$ & $(1,583,620,403)$ \\
\hline 15 & $768,608,839$ & $900,836,641$ & $(2,484,457,044)$ \\
\hline 16 & $987,251,899$ & $1,119,479,701$ & $(3,603,936,745)$ \\
\hline 17 & $1,088,502,443$ & $1,220,730,245$ & $(4,824,666,991)$ \\
\hline 18 & $1,078,771,394$ & $1,210,999,197$ & $(6,035,666,187)$ \\
\hline 19 & $1,068,687,444$ & $1,200,915,246$ & $(7,236,581,433)$ \\
\hline 20 & $1,059,145,620$ & $1,191,373,422$ & $(8,427,954,855)$ \\
\hline & & & \\
\hline
\end{tabular}

Karena sisa kas bersih pada tahun ke delapan tidak dapat dikurangi kas bersih tahun ke delapan, maka sisa kas bersih tahun ke tujuh dibagi kas bersih tahun ke delapan, yaitu: Maka Payback Period adalah 12 tahun 3 bulan. Tabel Rekapitulasi Perhitungan Hasil Analisis Kelayakan Investasi pada Gedung olahraga Tipe B Kabupaten Bangka.

Tabel 8 Rekapitulasi Hasil Kelayakan Investasi GOR Kabupaten Bangka

\begin{tabular}{|l|l|l|l|l|}
\hline No & Metoda & Kriteria & Hasil & Keputusan \\
\hline 1 & $\begin{array}{l}\text { Net Present } \\
\text { Value (NPV) }\end{array}$ & $\begin{array}{l}\text { Jika NPV positif, } \\
\text { maka investasi layak dilanjutkan }\end{array}$ & 30.433 .056 & Layak \\
\hline 3 & Payback Period & Jika di bawah & 12 tahun 3 bulan & Layak \\
\hline
\end{tabular}




\begin{tabular}{|l|l|l|l|l|}
\hline No & Metoda & Kriteria & Hasil & Keputusan \\
\hline (PBP) & $\begin{array}{l}\text { Payback maksimum usia } \\
\text { ekonomis sebesar 20 tahun maka } \\
\text { investasi layak } \\
\text { dilanjutkan }\end{array}$ & Layak \\
\hline 4 & $\begin{array}{l}\text { Internal Rate Of } \\
\text { Return (IRR) }\end{array}$ & $\begin{array}{l}\text { Jika IRR lebih besar dari tingkat } \\
\text { keuntungan yang } \\
\text { dikehendaki sebesar 7\%, maka } \\
\text { investasi layak dilanjutkan }\end{array}$ & $7.05 \%$ & \\
\hline
\end{tabular}

\section{KESIMPULAN}

Nilai Payback Periode (PP) adalah sebesar 12 tahun 3 bulan lebih kecil dari nilai ekonomis 20 tahun kemudian Nilai NPV pada Discount Factor 7\% sebesar Rp.30.433.056 dan pada Discount Factor 8\% sebesar -615.560 .014 baik secara $P P$ maupun NPV dan IRR Pembangunan gedung olahraga tipe B Kabupaten Bangka dikatakan layak karena nilai $N P V$ positif, pada discount factor $7 \%$ hasil positif dimana pembangunan gedung olahraga (GOR) layak dijalankan.

\section{UCAPAN TERIMAKASIH}

Ucapan terima kasih disampaikan kepada Lembaga Penelitian, Pengabdian Kepada Masyarakat, dan Penjaminan Mutu Pendidikan (LP3) Institut Teknologi Sumatera, yang telah memberikan support dana penelitian (Penelitian Hibah ITERA SMART Tahun 2019) sehingga pelaksanaan penelitian ini dapat berjalan dengan baik.

\section{DAFTAR PUSTAKA}

Gittinger, J.Prince. Adler, Hans A., 1990. Evaluasi Proyek, Terjemahan Soemarsono SR. Rineka Cipta. Jakarta
Husna, Suad, 1984. Studi Kelayakan Proyek. BPFE. Yogyakarta

PT.Multi Visi Karya, 2019, Studi Kelayakan Pembangunan Gedung Olah Raga (GOR) Kabupaten Bangka, Laporan Akhir", Kabupaten Bangka, Provinsi Kepulauan Bangka Belitung.

Ardina Rahmalia, Fahmi Akmal Hasani, Djoko Purwanto , Wahyudi Kushardjoko, 2016, Analisa Kelayakan Pembangunan Jalan Tol Pemalang Batang, Jurnal Karya Teknik Sipil , Volume 5, Nomor 1, Semarang

I kadek Sutika, I G.B. Wiksuana, Luh Gede Sri Artini, 2017, Studi Kelayakan Pembangunan Pusat Perbelanjaan Cokroaminoto, E-Jurnal Ekonomi dan Bisnis Universitas Udayana 6.2, Denpasar 